\title{
Sounding a Quietening: Breastfeeding Choreographies and the Sonic-Corporeal Dialogue of Maternal Experience ${ }^{1}$
}

\author{
AOIFE MCGRATH
}

Let Down (2018) is a practice-as-research (PaR) dance performance that communicates women's experiences of breastfeeding in Northern Ireland, a jurisdiction with one of the lowest breastfeeding rates in the world, due, in part, to the social stigma attached to breastfeeding in public. Choreographed in collaboration with a composer and social scientists, Let Down is a duet for two lactating women who dance alongside a digitally transposed and augmented soundscape of sonic aspects of maternal experience, and improvise to the live sounds produced by infants in the audience. The work responds to a 'quietening' of maternal corporeality in some Western societies through a feminist dramaturgy of sonic disruption that refigures intermedial relations between sound and movement in performance to make unheard experience sensible. Attending to the complex sociopolitical and affective terrain that informed the work's creation, I discuss how a methodology of 'quietening' developed during the choreographic process generated space for a dialogue between private and public spheres of experience. I propose that the methodological concept of quietening offers both an alternative approach to choreographies of affect, and a critical framework for questioning representations of socially 'quietened' corporealities.

What perceptual shifts occur in performance if we extend beyond visual representation of a corporeal practice to also listen to it, and a sonic dimension of experience is placed in dialogue with its danced embodiment? And if this corporeal practice is imbued with societal judgement and, often, personal shame - being inextricably bound up with complexities of societal taboos and manipulative and oppressive visual representations of female corporeality - what new opportunities for a refiguring of communication and reception emerge if expected relations between sound and movement are disrupted and disturbed? These questions were at the heart of my choreographic investigation into the relationship between the sonic and the corporeal in a practice-as-research $(\mathrm{PaR})$ dance performance, Let Down, that I created collaboratively with a team of artists and social scientists in 2018 in Belfast, Northern Ireland. Let Down is a performance about women's experiences of breastfeeding and is part of my wider, ongoing, PaR project on Dance and the Maternal, ${ }^{2}$ in which dance practice is the primary research methodology, allowing often untold and invisible embodied perspectives of the maternal to be articulated. ${ }^{3}$ The choreographic process for this work raised questions for $\mathrm{PaR}$ scholarship, and dance, theatre and 
performance studies more broadly, about the generative and disruptive potential of sonic choreographies of affect, and their ability to communicate quietened experiences of socially disruptive corporealities.

Let Down originated through a collaboration with psychologist Dr Jennifer Hanratty, and commissioning awards from the Being Human Festival (AHRC/British Academy), the Northern Ireland Mental Health Arts and Film Festival (NIMHAFF) and Breastival Belfast, a festival Hanratty co-founded to 'support and normalise' breastfeeding in Northern Ireland, a jurisdiction (along with the rest of the UK and Ireland) with the lowest breastfeeding rates in the world. ${ }^{4}$ The uncommonness of breastfeeding in Northern Ireland has been attributed, in part, to negative cultural and social attitudes towards breastfeeding, and women's embarrassment to breastfeed in public space. ${ }^{5}$ The affective environment surrounding breastfeeding in public in the UK, as human geographer Kate Boyer notes, creates a culture in which 'breastfeeding women are expected to act so as to maintain public comfort (i.e. the comfort of others) or risk censure'. ${ }^{6}$ Although the creative impetus for Let Down did not originate in breastfeeding advocacy per se, it did build from a desire to explore the deeply complex sociopolitical and affective terrain that surrounds breastfeeding, and to communicate women's often untold negative experiences of breastfeeding, or failure to breastfeed. ${ }^{7}$ The work was also choreographed as a counter to public shaming of breastfeeding women: former US president Donald Trump, for example, (in)famously called lawyer Elizabeth Beck 'disgusting' when she requested a break from questioning him during a deposition in 2011 so that she could pump breastmilk for her three-month-old baby, ${ }^{8}$ and Northern Irish MP Sammy Wilson - in response to a 2016 report recommending that women should be allowed to breastfeed in the House of Commons chamber of the British parliament - claimed that women who want to breastfeed in the chamber are 'voyeuristic' (he later amended this to 'exhibitionist'), explaining, 'to me, anyone who chooses to do it [breastfeeding] in the chamber rather than do it in the quietness of their office, is doing it for reasons other than simply feeding the child, to make a point'. ${ }^{9}$ Such public shaming has very real consequences for how societal attitudes to breastfeeding are formed and perpetuated, and as Sarah Ahmed points out in her study of the cultural politics of emotions that 'stick' to texts that circulate in the public domain, bodies (both individual and collective) are shaped by their contact with such othering narratives. ${ }^{10}$ Let Down explored how these narratives impinge on both societal mouldings and mothers' experiences of maternal corporeality.

The disturbing placement of blame on breastfeeding mothers for sexualized interpretations of breastfeeding in public, and a desire for women to remain in a space of 'quietness', ${ }^{11}$ aligns with feminist theorists' articulation of the threat posed by the 'monstrous maternal', whose 'alien materiality' is often represented as a figure of horror in Western society and visual culture. ${ }^{12}$ Elizabeth Grosz draws attention to Western societies' attitudes towards female bodies' flows of blood and milk, their 'seepage', as a disruptive 'site of potential social danger'. ${ }^{13}$ Attempting an alternative representation of maternal corporeality from the perspective of the mother within this fraught environment is a challenging task, with breastfeeding in particular, as Valerie 
Schmied notes, being a 'vexed feminist issue', with its 'hazardous' connections with 'biology, essentialism, and conservative arguments about women's reproductive and nurturing roles'. ${ }^{14}$ A central choreographic question explored in Let Down was how to communicate the internalization of societal judgement through a dance performance about breastfeeding in such a way as to make the affective and corporeal effects of these complex social relations on the maternal body visible and sensible. In answering this question, I was very aware both of the ethical concern of not being able to ask my son for his informed consent to be part of a breastfeeding 'performance', and of the conceptual dilemma inherent in simply reproducing the act of breastfeeding onstage; that is, the dilemma of reproducing a known and expected relationship with spectators that would possibly only accomplish exactly that - a replication without potential for further thought or movement, obscuring, once more, the affective terrain as experienced by breastfeeding women. In collaboration with composer Sorca McGrath, we therefore decided to explore an alternative approach, experimenting with isolating this maternal affective terrain by making it audible. The soundscape then became a central choreographic element in communicating women's experiences of breastfeeding and we sought to make sensible a dialogue between an embodied and sonic representation of, and response to, a societal quietening of maternal corporeality.

I mobilize the concept of 'quietening' as a way to encompass an analysis of both corporeal and auditory dimensions of maternal experience, and the term serves the dual purpose of referring both to the self-censorship of a breastfeeding mother's own movement and sound, and to Western societal expectations of the invisibility and silence of certain aspects of maternal corporeality. I also employ the term methodologically to describe a choreographic device developed in the work in which the uncoupling of an expected relationship between body and sound permits a quietening of the habitual societal expectations or narratives connected with it, allowing for an increased awareness of corporeal experience that can otherwise be muted.

\section{Sounding a multiplicity of breastfeeding experiences}

Scholarship at the intersection of maternal studies and psychosocial theory has highlighted the problematic positioning of the mother within much psychoanalytical and philosophical thought as a figure who must be rejected in the process of subjectivity formation. ${ }^{15}$ The mother becomes, as Lisa Baraitser suggests, 'a shadowy figure who seems to disappear from the many discourses that explicitly try to account for her. ${ }^{16}$ Countering this disappearance, Let Down placed mothers' experiences centre stage in a duet for two lactating women - dancer and choreographer Paula O'Reilly and myself - that was in dialogue with both live and recorded sound and voice. Barbara Browning, following her own experience of breastfeeding, and writing about the significance of breastmilk in Afro-Brazilian curative dances, notes the 'insufficiency, the meagreness of individual experience in grappling with political questions' related to the topic of breastfeeding, and the need for an understanding of 'the fluidity of cultural forms, as well as alternative models for understanding literal bodily fluids'. ${ }^{17}$ Embracing this fluidity, and a desire to 'move through and then 
beyond one's own embodied perspective', ${ }^{18}$ the development of the work's articulation of a quietening included verbatim excerpts from interviews conducted by sociologist Maria Herron with both breastfeeding and non-breastfeeding mothers across the island of Ireland and the UK. ${ }^{19}$ The creative team was also granted access to unpublished Northern Ireland Public Health Authority qualitative research on breastfeeding through our collaboration with Hanratty at the Centre for Evidence and Social Innovation at Queen's University Belfast (QUB). The inclusion of recorded excerpts from this data allowed the voices of a wide range of women and their different breastfeeding (or non-breastfeeding) experiences to be present alongside the dance of Paula and myself.

Speaking of the phenomenological relationship between the auditory and the visual, Don Ihde suggests that 'an inquiry into the auditory is also an inquiry into the invisible. Listening makes the invisible present in a way similar to the presence of the mute in vision'. ${ }^{20}$ Let Down experimented with using sound in several ways, including both the recorded soundscape and live, improvised sounds produced by babes-inarms in the audience during the performance. Creating a performance of silenced maternal corporeality engages in what Uri McMillan argues to be a 'sonic of dissent', which, in its voicing of ordinarily concealed experience, produces 'a form of embodied knowledge that momentarily trouble[s]' existing narratives and 'distinct circuits of spectatorship and performance.. ${ }^{21}$ Let Down's soundscape employed this dissensual sonic approach to communicate mothers' often concealed or untold affective experiences of public breastfeeding and breastmilk pumping, which can be, as Maggie Nelson suggests, a 'sharply private activity ... that is physically and emotionally challenging', yet a necessary one for breastfeeding women who wish to (or must) continue to labour across both private and public spheres of their lives. ${ }^{22}$ Through processes of transposition, digital augmentation and amplification, the piece created a sonic environment for the spectator that drew attention to both the corporeal labour required to breastfeed, and the contradictory societal expectations that women should breastfeed, but that this labour be kept silent and out of sight, especially in public.

\section{Contextualizing the maternal across private and public spheres}

In developing a methodology of quietening, this project is in conversation with recent research on the relationship between the performance and the maternal, which Lena Šimic and Emily Underwood-Lee identify as representing a search for 'maternal performance aesthetics' that question 'the collision between the lived and the staged maternal artists' processes and methodologies [and] the politics and ethics of "maternal performance making" and of making work while ... looking after children'. ${ }^{23}$ It also seeks to contribute to the project, as articulated by Amber E. Kinser, Kryn Freehling-Burton and Terri Hawkes in Performing Motherhood (2014), of broadening academic and artistic interventions into the performance of motherhood, 'to imagine, engage, and contest ways that social performance(s) and maternal life are mutually infusive'. ${ }^{24}$ Auto-ethnographic documentation of my own experience of breastfeeding and maternal subjectivity generated the embodied roots for the choreography of Let Down; I was a breastfeeding mother when I co-performed 
the work and am 'still' breastfeeding my five-year-old son at the time of writing this article. $^{25}$ Choreographing a dance that placed my own subjective experience of breastfeeding at its heart was a tricky process, both from a practical perspective and from a political, personal viewpoint as an artist-mother working in academia. Rehearsals for, and performances of, Let Down took place at QUB, and Paula and I sometimes had to bring our toddlers, and all of their necessary accoutrements and unpredictable movements and sounds, into the university rehearsal studio. In addition to experiencing the usual difficulties of trying to find time to engage in $\mathrm{PaR}$ work as part of an academic workload, rehearsals for Let Down also made me acutely aware of institutional expectations, and my own internalized perceptions, of what kinds of identities (especially for female academics) and bodies (with their associated movements and sounds) are considered normal within the usually quiet research spaces of universities. As Laura Endacott points out, 'The university environment is an unforgiving place ... built on a male model of performance,, ${ }^{26}$ and a feeling of intrusion was one I continually worked with and against throughout the choreographic process for Let Down, both in my workplace and within the broader, societal context of breastfeeding in public.

Writing about how different people's corporealities define their experience of public space in Western societies, Amanda Barnes Cook notes that 'the problematic imperative of the public sphere, policed through public norms, is that anyone is welcome - so long as they act like the ideal public actor: a heterosexual, white, able-bodied man'. ${ }^{27}$ Cook points out that this imperative is 'especially pernicious' for anyone not in the position to distance themselves from their bodies: 'Breastfeeding mothers, pregnant women, disabled people, people of color, and queer people are all conspicuous in the public sphere because of their bodies and their bodily performance. ${ }^{28}$ Unlike in many territories in the global South, or EU countries with more supportive cultures and legislation for breastfeeding, such as Sweden, Norway or Denmark, breastfeeding women are not commonly seen breastfeeding in public across the island of Ireland, underscoring this sense of conspicuousness for women (and their breastfeeding children) who do. ${ }^{29}$ Similarly, laws explicitly addressing breastfeeding in public are becoming a relatively common phenomenon globally, with countries in the global South, such as India and Vietnam, leading the way in implementing legislation both to support mothers to breastfeed, and to regulate the marketing of breastmilk substitutes. ${ }^{30}$ However, Ireland and Northern Ireland lag behind in terms of explicit legislation for breastfeeding, a situation that raises troubling questions when the neo-liberal market context of infant formula being big business for the dairy industry is considered: infant formula represents 35 per cent of Ireland's total dairy exports, and the industry produces 10 per cent of all global infant formula, including 17 per cent of the infant formula consumed in China. ${ }^{31}$ If more mothers breastfeed, fewer mothers require infant formula, resulting in lower profits for an important national industry.

Highlighting the similarly 'spotty' cover of public breastfeeding legislation that protects women from indecency charges in the US (where the production of infant formula is also a lucrative business), and considering further reasons for a reluctance to support public breastfeeding, Kukla points out that 'new motherhood does not 
erase the sexualized status of the female breast in [Western] culture, nor does it mitigate women's sexual vulnerability in public spaces. Accordingly, breastfeeding opens women to offended, sexualized, and even violent and punitive gazes'. ${ }^{32}$ Kukla also highlights that when breastfeeding in public, women can be seen to transgress the expected location of maternal labour in the domestic space, a space 'characterized by a set of material arrangements, placements, and boundaries, but also by the social life and the kinds of bodies that inhabit it and give it its form, as well as by its segregation from work space and public gathering space. ${ }^{33}$ The choreographic process for Let Down traversed these numerous contextual threads and their intricate web of concerns across both private and public spheres. In the following sections, I delve further into our creative process for the piece to analyse how a dialogue between the sonic and the corporeal assisted in the navigation of this complex terrain, and how focusing on the relation between movement and sound allowed for an exploration of the shaping and quietening of the breastfeeding maternal body.

\section{Dancing decomposition: separating the sonic and the corporeal}

\section{I thought it was OK}

I could understand the reasons

There might be young children, or a nervous man seeing

This small piece of flesh that they weren't quite expecting

So I whispered and tiptoed with nervous discretion

(Hollie McNish, Embarrassed) $^{34}$

In the poem cited above, Hollie McNish writes about feeling pressured to breastfeed her six-month-old baby in a toilet cubicle rather than in the public space of a café, articulating the corporeal internalization by a breastfeeding mother of societal feelings of embarrassment towards breastfeeding. ${ }^{35}$ In an attempt to make her public breastfeeding discreet and socially acceptable, the mother reconfigures her sonic and corporeal presence - she whispers and tiptoes. The sonic aspect of breastfeeding is one not usually thought of, but in the context of Let Down's exploration of the social stigma related to breastfeeding in public, and mothers' experiences of shame, it became a crucial one. Breastfeeding infants can make many sounds as they feed, ranging from the tiny, aspirated 'keh' sound that new mothers are told to listen for to ensure that newborn babies are latching correctly and swallowing milk, ${ }^{36}$ to vocalizations of deep pleasure and appreciation, or screams of frustration and desperation if milk is flowing too quickly or not fast enough. Breastfeeding mothers also develop their own repertoire of sounds (and movements) to soothe, distract or lull their infants to sleep. In Let Down we focused on this sonic dimension of breastfeeding to capture the maternal body's function as a 'material sound system'. In considering the relationship between music and the maternal in the mother-daughter relationship, Elizabeth Wood (following Irigaray) proposes that

we need to revisit the maternal body ... not to murder the mother or experience maternity as a symbolic death, but to re-narrativize the biological ground of the 
mother's body in such a way as to render it as material (as opposed to essentializing it), and therefore holding the possibility for a variety of psychic structures and social and political relations. ${ }^{37}$

She proposes the maternal body as a material sound system, approaching the task of 'thinking back through the maternal body' as an 'act of decomposition: one that breaks up or disintegrates things already composite - things that have adhered or become coherent through the activity and experience of mother-daughter composition under patriarchy'. ${ }^{38}$ Although Let Down's focus was rooted in lending visibility to the mother's experience from her own perspective, rather than viewing the experience through the mother-child dyad, an embodied research process inevitably also necessitated an exploration of the relational aspects of breastfeeding, and, during the creation of the soundscape for Let Down, Wood's concept of decomposition became a key element.

To build the material sound system of the breastfeeding body, the composer and I made field recordings of the sounds of me breastfeeding my son in different locations, both inside and outside my home, and the resulting score was a constant soundscape element throughout the work, which the composer distorted electronically so that it was sometimes amplified, and sometimes barely audible when combined with other choreographic and sonic elements. These recordings of breastfeeding sounds became one of only two literal representations of breastfeeding in the piece (the other being projected images of Madonna Lactans (Nursing Madonna) paintings, discussed later), and their electronic manipulation and amplification in the soundscape functioned not only to challenge their quietening, but also to decouple the sounds of breastfeeding from the physical action that produced them. This act of decomposition - breaking up the coherence of usual patterns of activity - allowed the connection of these sounds with experiences of social stigma to be danced into view by the maternal body.

While searching for a way to embody the feelings experienced when breastfeeding in public during our rehearsal process, Paula and I took our cue from what we called the 'shirt choreography' that breastfeeding mothers dance while attempting to make their feeding socially acceptable to others - the small movements, often motivated by feelings of embarrassment and shame, that are performed to minimize the circumference of 'that small piece of flesh' on the breast that is visible around the infant's mouth while they feed, ${ }^{39}$ and the manoeuvres made to shield breastfeeding from unwanted gazes. To the accompaniment of the recorded breastfeeding sounds, this movement idea was developed into a series of multiple repetitions of tiny, simple adjustments to our clothing: slowly lifting a shirt off the shoulder by an inch and releasing it again; pulling at the bottom hem of a T-shirt to make it a little longer; making innumerable, minuscule tweaks to how a top sits across the breasts. This silent choreography of discomfort danced to a soundscape created from the material sound system of the breastfeeding body communicated an experience of breastfeeding in public without either visually representing breastfeeding or sonically indexing the maternal affective experience. In breaking up the composite, this act of choreographic decomposition, following Wood, sought to perform a new act of composition that 
'allows other possibilities or expansions of understanding and reciprocation to take place'. ${ }^{40}$ In breaking apart the expected relationship between sounds and movements of breastfeeding, we endeavoured to quieten debates and affects surrounding the act that would usually stick to its performance, offering the spectator an opportunity to view, and review, their effect on maternal corporeality.

\section{Mechanical sounds of disconnect}

Uncanny aspects of sonic and embodied experiences of breastfeeding, such as spontaneous lactation and the use of breast pumps, became another site of choreographic investigation, allowing biological and mechanical dimensions to be explored. The title of the work - Let Down - references both the lack of familial and societal support experienced by breastfeeding women communicated in the survey and interview data, and the biological reflex that occurs in the body to release milk from the breast:

When your baby nurses, nerves in the nipple and areola send a signal to the pituitary to release a hormone called oxytocin. Oxytocin causes those little muscles around the alveoli to squeeze, building milk pressure inside the breast and creating a milk release (or milk ejection reflex or let-down). The tiny ducts yawn open as milk spurts down them. You might feel a tingling in your breasts or shoulder blades, you might feel thirsty or sleepy ... or you might feel nothing at all. In the early weeks a milk release may be triggered just by thinking about nursing or by hearing a baby (any baby!) cry. Your body wants to breastfeed! ${ }^{41}$

When I first read this explanation of the let-down in the breastfeeding 'bible', The Womanly Art of Breastfeeding, before my son's birth, I was fascinated and also slightly perturbed. The process describes a wondrous dance at the heart of breastfeeding, a contraction of muscle cells followed by a 'yawning' release of milk. Contraction and release: the physiological fundamentals of movement. But there also seemed to be an odd positioning of the body apart from the self: 'your body wants to breastfeed!' This upbeat exclamation (or was it an exhortation?) presented the possibility that this new maternal body might have demands at odds with what 'I' wanted. Esther Leslie and Melanie Jackson, whose illuminating collaborative project on the topic of milk spans sculpture, animation, and gallery installations, note that, 'Like the act of reproduction, lactation is the enactment of a splitting, of a formation of self and part-self that is to become other. It disrupts the dominant motif of the bounded body, of sovereign individuality'. ${ }^{42}$ In addition to this disorienting experience of 'splitting', the thought of my body producing an uncontrollable flow of milk in response to any baby's sounds lent the process a strangely alien, mechanical slant. It became no less strange after my first experience of spontaneous lactation, as my son's cries from another room caused milk to flow with astonishing abundance before I could reach him. Browning writes of the 'uncanny' nature of her own experience of a let-down triggered by an emotional response: 'My body is acting on its own. I am not moving, but I am performing a dance'. ${ }^{43}$ The triggering of a 
physical process by the sound of a baby's cry - the release of hormones, the cells contracting and opening, the production of milk - just like the effects of public shaming, all of this is experienced corporeally by the breastfeeding mother, but may be completely invisible to an observer. The experience of pumping breastmilk when apart from my son introduced a further mechanical dimension.

While pumping in my work office and in the toilets of the train on my daily commute, I became acutely sensitive to the mechanical sounds of my breast pump, whose adjustable rhythms (designed to simulate the rhythms of a baby's suckling) I never quite managed to 'calibrate' successfully, and whose advertised 'discreet' grinding whine I felt certain could nevertheless be heard in my colleagues' neighbouring offices, or outside the train toilet door. The experience of having to publicly perform acts that social decorum confines to the domestic sphere brings to mind Homi Bhabha's discussion of the 'unhomely moments' created by the effects of 'enforced social accommodation' - an experience of 'displacement' in which 'the border between home and world becomes confused, and, uncannily, the private and the public become part of each other, forcing upon us a vision as divided as it is disorienting. ${ }^{44}$ Bhabha suggests that in the 'stirrings of the unhomely, another world becomes visible', and in articulating disorienting experiences of breastfeeding, Let Down made visible 'another world' experienced by breastfeeding mothers. ${ }^{45}$ In attempting to dance the breastfeeding body's autonomous response to a baby's cry, and the uncomfortable merging of body and machine while pumping, the dialogue between sound and body became the most creatively fruitful site to explore for finding a way to respond to, and try to communicate, these 'unnatural', unhomely, corporeal experiences. In our search for sonic articulation of the other world of the unhomely breast pump we moved beyond the material sound system of the breastfeeding mother's body. To foreground the mechanical aspects of pumping, we conducted field recordings of the sounds of my family car getting an oil change in a mechanic's garage. The composer then created a jarring, grinding rhythm from sounds of the garage lift being operated and an eerily melodic track of oil (milk) drips (catch the milk!) draining from the vehicle into a metal pan. The composition created from these loud procedures of mechanical maintenance, involving fluidic excretion from a metal body, served to transpose and amplify the affective experience of the use of breast pumps. The sonic body made communicable an uncanny experience that was otherwise difficult to express within the visual limitations of the maternal body in performance.

\section{Sounding a lost corporeal history}

The creation of the soundtrack of the unhomely pump inspired the development of movement articulating 'unnatural' aspects of breastfeeding. Consulting the interview data from Public Health Authority reports it became clear that due to the very low rate of breastfeeding in Northern Ireland, women felt disconnected from earlier generations of breastfeeding mothers and often had no real-life example of breastfeeding to observe. ${ }^{46}$ In her discussion of how the 'naturalness' of breastfeeding 
is, in fact, a cultural and political construct, Browning draws a connection with Marcel Mauss's writing on 'Body Techniques', in which he 'urges European readers to denaturalize their understanding of a variety of cultural forms', so that they realize that 'things we find natural have a historical origin'. ${ }^{47}$ Similarly, Nancy Scheper-Hughes explains that ' $[b]$ reast-feeding is a form of body praxis. Like swimming, dancing, or making love, breast-feeding must be learned, and the knowledge of "how" to do it comfortably and well (though with many cultural variations) can be lost'. ${ }^{48}$ During our research process, we hunted for traces of this (often) lost thread of corporeal knowledge, and our dramaturge, Emily DeDakis, found historical representations of breastfeeding in the visual arts in the form of Madonna Lactans iconography: Catholic paintings dating from between the twelfth and seventeenth centuries that show Mary breastfeeding the infant Jesus, or sometimes squirting breastmilk (across an impressive distance) into the mouth of a bishop, saint, or pontiff. As a contemporary viewer, I found these images to be unsettlingly paradoxical in that they carry the baggage of a long history of religious institutional oppression and abuse of women, especially in an Irish context, while simultaneously giving a glimpse of a time in which public breastfeeding was culturally acceptable. ${ }^{49}$ They also highlight how squeamish Western societies have become about images of breastfeeding, how it now seems almost impossible to escape a potentially sexualized reading of a breastfeeding image, and how visually quietened breastfeeding has become as a result. ${ }^{50}$ The image in Fig. 1 is a Madonna Lactans painting from 1598 by the Italian artist Sofonisba Anguissola, which was widely admired and copied by contemporary artists for her 'realistic' depiction of breastfeeding.

In her analysis of Anguissola's Madonna and Child, Naomi Yavneh argues that ' $[\mathrm{b}]$ reastfeeding, mother and child share a ubiquitous quotidian act, and in so doing insist upon their own flesh and blood selves'. ${ }^{51}$ While working with this and other Madonna Lactans images in the rehearsal room, we tried to re-member a lost celebration of breastfeeding as quotidian by mimicking the breastfeeding hand poses they depicted (Anguissola's painting depicts a 'V-hold', for example), in a knowingly doomed attempt to connect with some ghost of a historical corporeal knowledge commons. Our failures to replicate these poses in rehearsals prompted the idea for a dance prefaced by the projection of a series of rapidly changing Madonna Lactans images, which we tried, and failed, to accurately mirror in an improvised response. This approach also drew on findings from the interview data, and Paula's and my own personal experiences, which showed that many mothers struggle to learn breastfeeding holds through reading breastfeeding how-to books or trying to decipher illustrations from poorly photocopied handouts distributed at prenatal classes. Learning a corporeal technique through a textual representation of it, rather than through human-to-human interaction with supportive and guiding voice and touch, places a disconnecting and mechanically oriented structure at the heart of the breastfeeding learning experience for many mothers, especially those with no access to expensive lactation consultants or breastfeeding support groups. When breastfeeding does not work, mothers then blame themselves for not being able to perform this supposedly natural act, feeling that their bodies have failed themselves 


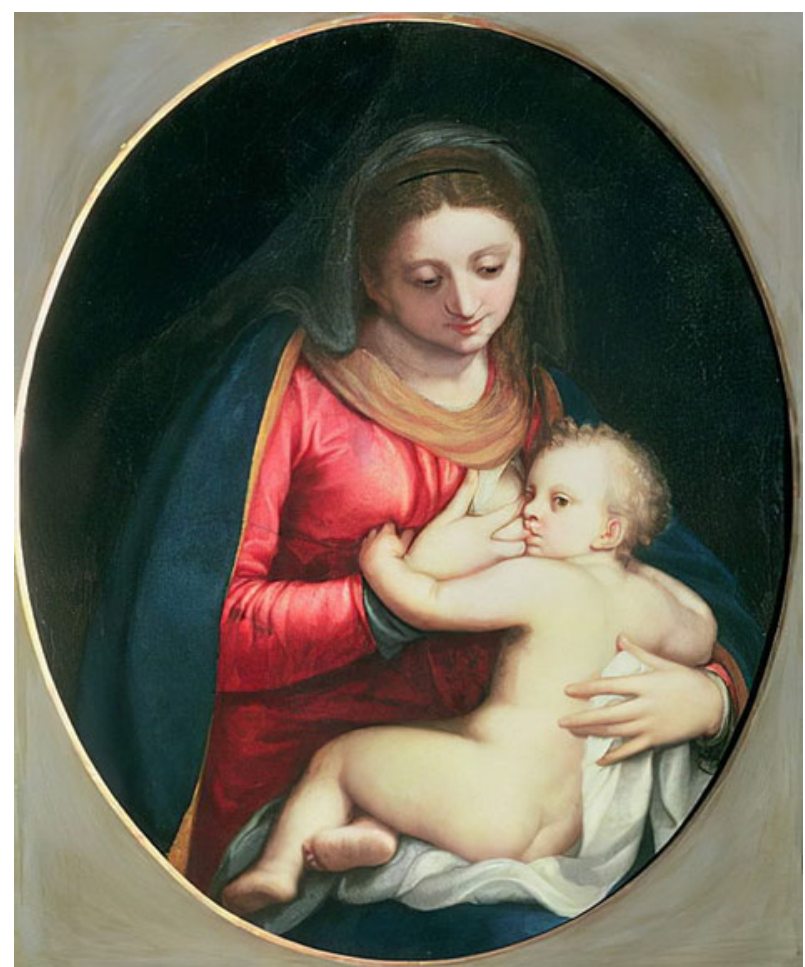

FIG. 1 Sofonisba Anguissola (Cremona, Italy), Madonna and Child (1598). Currently part of the collection at the Museum of Fine Arts, Budapest.

and their baby. ${ }^{52}$ The shame connected with this experience of failure is, unsurprisingly, hard to articulate, and becomes another instance of self-quietening. The reality that breastfeeding can be difficult is also conspicuously absent and quietened in the predominant, promotional narratives of 'breast is best', and advertisement images of beatifically smiling mothers (reminiscent of the Madonna Lactans), 'in white negligees or other bedroom garb, sitting in either a rocking chair or an upper-middle-class nursery, or ... in an empty nonspace against a blank or abstract background'. ${ }^{53}$ Articulating these feelings of disconnect and corporeal/mechanical failure, our Madonna Lactans hold-dance was accompanied visually by technical images taken from car manuals, and sonically by the 'unhomely pump' field recordings of the oil change in a mechanic's garage (see Figs 2 and 3).

This soundscape aimed to make audible both women's experiences of the mechanization of breastfeeding and the painful severance with the historical transference of breastfeeding knowledge through the body. ${ }^{54}$ In transposing the sounds of breastfeeding onto sounds of automation, Let Down attempted to reconstruct - in a self-consciously Frankenstein-like manner - a connection with a lost corporeal past. Susan Leigh Foster proposes that the dance historian's body 

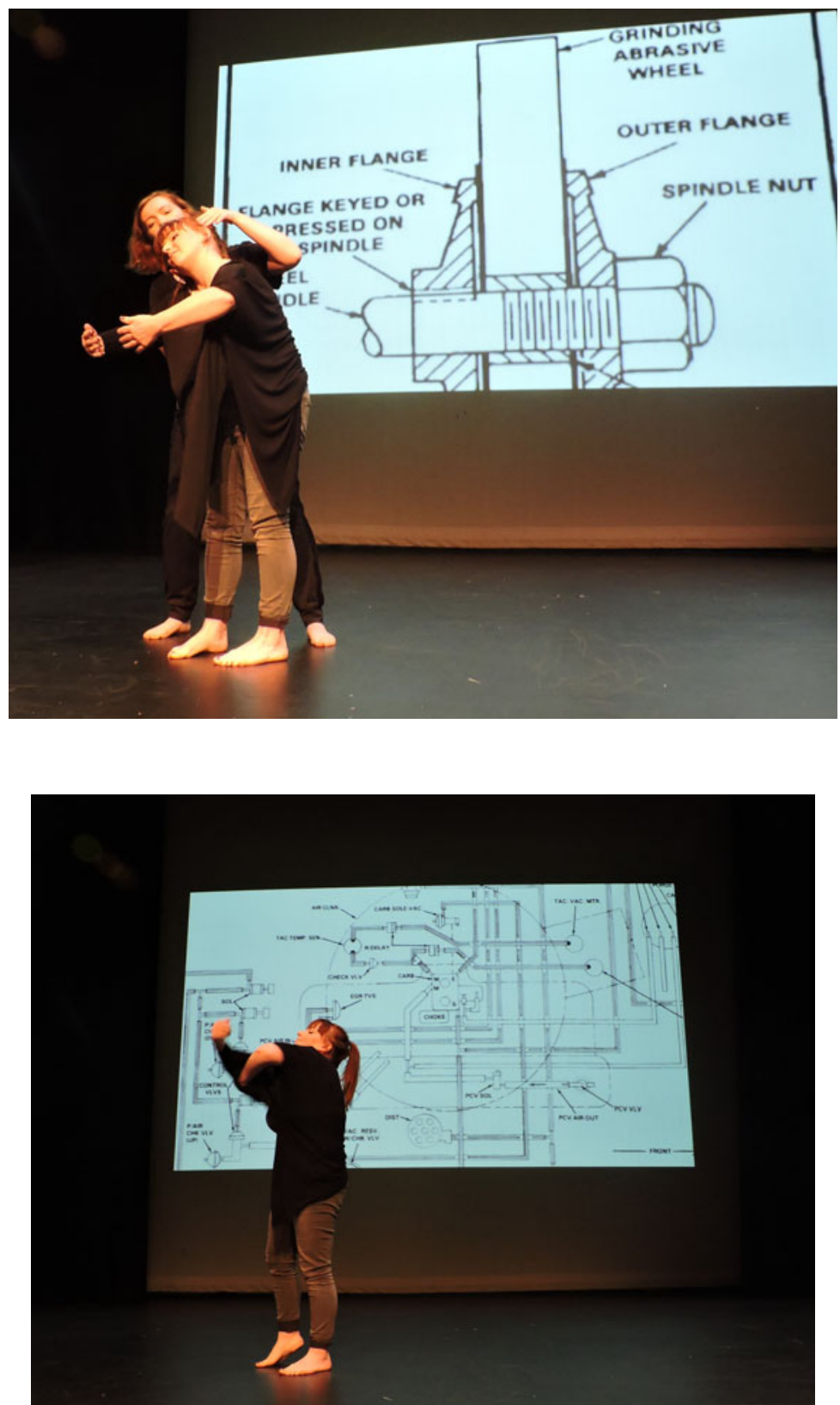

FIGS. 2, 3 Images from the 'hold-dance' in Let Down showing the use of technical drawings from car engine manuals as a visual backdrop to the dancers' attempts at imitating the breastfeeding holds represented in Madonna Lactans paintings (the author on the left and Paula O'Reilly on the right above, O'Reilly below). The 'hold-dance' was accompanied by a soundscape made with field recordings of an oil change being carried out on a car. Both images from the performance at the Being Human Festival, 24 November 2018, Brian Friel Theatre, Belfast. Photographs by Benjamin Lichtenberg. 
wants to consort with dead bodies, wants to know from them: What must it have felt like to move among those things, in those patterns, desiring those proficiencies ... A historian's body wants to inhabit these vanished bodies for specific reasons. It wants to know where it stands, how it came to stand there, what its options for moving might be. It wants those dead bodies to lend a hand in deciphering its own present predicaments and in staging some future possibilities. ${ }^{55}$

In our attempts to embody the vanished corporeal knowledge and history depicted in Madonna Lactans images we lent visibility to the contemporary quietening of the difficulties of breastfeeding. Simultaneously, the soundscape made audible an alternative history of breastfeeding that contradicts the 'breastfeeding-is-natural' mantra of breastfeeding literature and advertisements, sounding the quietened, unnatural realities of uncanny and mechanized elements. Jonathan Sterne, in his exploration of sound cultures and sound reproduction, argues that the construction of an audible past is connected with histories of 'bodily experience': 'the history of sound implies a history of the body. ${ }^{56}$ Let Down's experiments with an alternative sonic experience of breastfeeding drew attention to the cultural aspects of its historical development. As Sterne suggests, 'The history of sound provides some of the best evidence for a dynamic history of the body because it traverses the nature/culture divide: it demonstrates that the transformation of people's physical attributes is part of cultural history. ${ }^{57}$ The loud machine sounds in Let Down highlighted aspects of the cultural history of breastfeeding that are often untold, sounding women's perception of the inadmissibility - the quietening - of breastfeeding sounds in environments outside the domestic sphere.

\section{Dancing time and sonic interruptions}

Sarah Manguso, in her diary writing about the profound changes in subjectivity that occur through aspects of motherhood such as breastfeeding, reflects, 'In my experience nursing is waiting. The mother becomes the background against which the baby lives, becomes time. ${ }^{58}$ Focusing on the effects of repetition in this transition, Baraitser proposes that the 'time of repetition' in maternal caring becomes 'the time of mattering, as opposed to the meaningless time of reproduction', but that this time 'can be felt as obdurate, distinctively uncertain in its outcome, both intensive and "empty", and tethered by the pace of the development of another' ${ }^{59}$ This tethering, and the experience of a shifting relationship with time, were embodied in a section of Let Down that included the projection onto a large scrim of a one-month excerpt of a breastfeeding diary that I obsessively kept for the first six months of my son's life. This document, created as a note on my phone, charted every detail of his defecation, urination, duration of sleep, and instances of reflux vomiting, and my own instances of blebs and mastitis. ${ }^{60}$ After I shared this document with the creative team, it became clear that, although essentially a factual list of corporeal events, the diary (including its liberal seasoning of emojis and expletives) also offered a mapping artefact of the emotional and psychological terrain experienced by a first-time mum dealing with the loss of control over her life as she knew it, and her (futile) search for some structure 
amidst the unknowns of a new reality. In this way it functioned like the artefacts of 'self-documentation' presented in Mary Kelly's seminal work Post-partum Document (1973-9), in which she exhibited (amongst other objects) analysed faecal stains and infant-formula feeding charts of her son - not, as Kelly explains, to represent some 'unified, transcendental subject of autobiography', but rather as documentation of a 'de-centered, socially constituted subject of a mutual discourse'. ${ }^{61}$ The breastfeeding diary in Let Down performed discursively in its echoing of findings from the interview data showing the societal pressures felt by breastfeeding mothers to provide evidence of how much breastmilk their babies are drinking - an impossible quantifying task for a breastfeeding mother.

In performance, the breastfeeding diary entries scrolled past in a crawl-text fashion, extending up and beyond legibility into the endless time and space of a white-out. While the text progressed, Paula stood in front of it, silently and motionlessly, reading with the audience (see Fig. 4). Time was seen to be measured solely through the actions of my son, in the durations of his breastfeeds (on left or right breast), and durations of his sleep across a continuous twenty-four-hour span that collapsed any difference between night and day, with the many typos evidencing my exhaustion and one-handed phone-writing moves made at odd, breastfeeding-constricted angles.

The soundscape at this point was generated from the field recordings of single oil drips, played at irregular intervals at a very low volume. This monotonous,

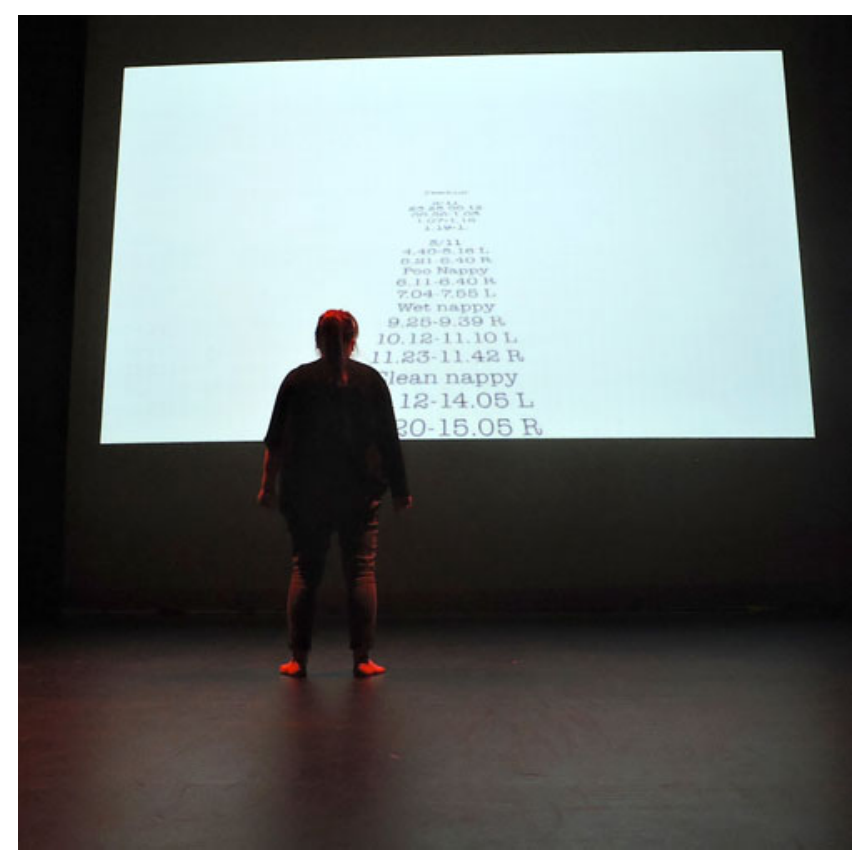

FIG. 4 Paula O'Reilly at the moment the breastfeeding diary excerpt begins to scroll in Let Down. Performance at the Northern Ireland Human Rights Festival, Belfast, 9 December 2018. Photograph by Benjamin Lichtenberg. 
almost-but-not-quite silence referenced the endlessly long, never-silent nights of the early days of breastfeeding. It also served to amplify the live soundscape contributions of babies in the audience. Not wanting parents and carers in the audience to have to worry about any sounds their babies might make during the show, we decided to include babies' spontaneous sounds as an integral - if unpredictable - part of the soundscape, with all of their sounds becoming a generative, improvisatory element that affected the movements of Paula and myself. ${ }^{62}$ In this breastfeeding diary section, Paula would react to sounds made by babies with small adjustments to her stance, which ultimately moved her from an upright standing position with her back to the audience, through an excruciatingly slow back-bend, to me catching her at the last second before she fell out of the bend to the floor. The timing for this drawn-out transition was dictated by the sounds made by the babies in the audience, and was an attempt to embody a response to Didier Anzieu's concept of the 'sonorous envelope' - the corporeal 'sound bath' experienced by a child when it cries and is comforted by a mother - from the perspective of the mother or carer. ${ }^{63}$ As Baraitser points out, 'something inevitably has been skimmed over and lost' in Anzieu's focus on the infant's experience of this sound bath, which makes no consideration of the mother's experience. ${ }^{64}$ Baraitser asks of the interruption experienced by mothers when they hear their baby's cry,

How does the cry enter her? How does her initial somatic response get converted into a pattern of thinking, as she begins to juggle with what to do, whether to feed on demand [or] whether to try another form of soothing as she knows she has just fed the baby and he cannot be hungry? ${ }^{65}$

Let Down's placement of focus on the mother's experience through interruption and improvisation embodied the skimmed-over and lost maternal experience of this sonic relationship between mother and child. Keeping the sonic and corporeal elements of an improvised choreography of this relationship at a distance from one another through their respective placement in the audience and onstage allowed the experience of the mother to be isolated and foregrounded. The fitful progression of the precarious back-bend became a corporealization of the effects of an infant's sonic interruptions on the mother, and the inclusion of infants' cries, gurgles and coos became a participatory soundscape for improvisation, highlighting quietened aspects of maternal experience.

\section{Conclusion: 'quietening' as an invitation for dialogue}

Woods argues that paying attention to the sounds that emanate from a body's materiality 'can provide a point of entry or access to the body and an important and powerful coding system, one that allows women to stake a claim in the highly politicized struggle to define ... the maternal body'. ${ }^{66}$ Through Let Down's experimentation with how to make quietened aspects of maternal corporeality visible through sound and movement, a choreographic methodology was developed that contributes a potential dual process of self- and social redefinition of how maternal corporeal experience is communicated. 
Separating sonic and corporeal elements of breastfeeding experiences in performance allowed the combined representation of, and dialogue between, interior (invisible/ untold/quietened) and exterior (visible/communicated/public) aspects. In Sterne's writing on the relationship between sound and the body, he 'turns away' from 'attempts to recover and describe people's interior experience of listening - an auditory past - toward the social and cultural grounds of sonic experience. ${ }^{67}$ In Let Down, we found a way to communicate precisely this interior experience while placing it in conversation with the sociocultural context of breastfeeding in Northern Ireland. Thinking through Sterne's distinction between the audible and the auditory was useful in developing a methodology of quietening in the choreographic process, as it helped give shape to the interweaving of self-quietening and social silencing of breastfeeding experience from both a sonic and a corporeal perspective. Sterne notes that 'the elusive inside world of sound - the sonorous, the auditory, the heard, the very density of sonic experience - emerges and becomes perceptible only through its exteriors' ${ }^{68}$ In Let Down, PaR dance investigations created a dynamic and disruptive site for experimenting with the communication of this merging of the interior and exterior of corporeal and sonic experience. Bringing attention to the sonic experience of breastfeeding from the perspective of the sound environment experienced by the breastfeeding mother allowed the creation of a sounding body that could be separated from the dancing body and placed in dialogue with it.

In his discussion of the 'gap' between the auditory and the visual in certain dance works, Jeroen Peeters considers Jean-Luc Nancy's reflection on painted portraits: 'A portrait is deprived of the person's voice, but makes the sonority of silence heard that reminds us of the irreducible "not-totality" of the arts. The latter opens up an endless resonance between different media'. ${ }^{69}$ In its experiments with the subtraction of sounds produced by breastfeeding from the moving body dancing about breastfeeding, Let Down created a dialogue between sound and movement that harnessed the resonance between the two media. This quietening of the maternal body - the uncoupling of expected relations between the sonic and corporeal in its performance, and resultant uncoupling, through an act of decomposition, from narratives of shame, blame and failure - produced a 'sonority of silence' for the movements of the breastfeeding dancers, with silence understood, as Nancy proposes, 'not as a privation, but as an arrangement of resonance. ${ }^{70}$ The resonance between dance and sound in Let Down offered a different view and sonic experience of the maternal body - a break with the expected - in which both a quietening of usual societal judgements and debates could occur, and in which unheard affective experience of breastfeeding mothers could be seen and amplified.

Attending to the material sound system of the body through a methodology of quietening offers an alternative approach to the choreography of affective experience. Through its refiguring of intermedial relations between the sonic and the corporeal in performance, quietening offers a feminist dramaturgy of disruption that works to destabilize enduring and seemingly ineradicable societal perceptions and judgements. It allows participants to listen to a sonic reimagining of personal, corporeal experience, while simultaneously viewing the corporeal reconfigurations that this 
experience necessitates. Through this tactic of uncoupling - dismantling and refiguring - quietening affords evasion of affective residues and narratives that would stick to a solely visually oriented representation, allowing the unheard to matter. Quietening also dwells in the unhomely collisions of social and private spheres, exposing the complex terrain of restrictive societal rules and expectations that maternal, and all 'othered', corporealities must navigate. The often discomforting resonances that emerge from this process raise further questions about aesthetic representations of the maternal (from the sanitized to the monstrous), and representations of female corporeality in performance and visual media more broadly. The sonic-corporeal dialogue of quietening generates a shared, intermedial space for these questions, in which quietened disruptive and cacophonous realities of embodied female experience can be acknowledged and sounded.

NOTES

$1 \quad$ My sincere thanks to my fellow editors of this special issue, the TRI editing team, and the two anonymous peer reviewers for all of their attentive and supportive feedback during the development of this article. This project began with a symposium I curated on Dance and the Maternal at Queen's University Belfast (QUB) in 2017 (supported by a QUB Faculty Research Initiative Fund award), which led to the first performance project about women's experiences of time in pregnancy, With/in: body + time (2018), co-choreographed and performed by Aisling McCormick when she was thirty-eight weeks pregnant. Let Down (AHRC/BA Being Human Festival) is the second performance project in this series, and I am currently working on a third piece, Impossible Worlds (AHRC/Future Screens NI), in collaboration with filmmaker Dee Harvey, exploring the use of dance and VR film to communicate women's experiences of post-partum depression, and a fourth work about loss and maternal grief that is created at cillin burial sites of unbaptized 'limbo' babies in Ireland.

3 Epistemological enquiry into choreographic practice-as-research is a growing field of discourse in dance studies. See, for example, Anna Pakes, 'Knowing through Dance-Making: Choreography, Practical Knowledge and Practice-as-Research', in Jo Butterworth and Liesbeth Wildschut, eds., Contemporary Choreography: A Critical Reader (Oxon: Routledge, 2009), pp. 10-22; Kim Vincs, 'Rhizome/Myzone: A Case Study in Studio-Based Dance Research', in Estelle Barrett and Barbara Bolt, eds., Practice as Research: Approaches to Creative Arts Enquiry (London: I. B.Tauris, 2010), pp. 99-112; and Hetty Blades and Emma Meehan, eds., Performing Process: Sharing Dance and Choreographic Practice (Bristol: Intellect, 2018). See the Breastival website at https://breastival.co.uk, accessed 20 October 2020.

$5 \quad$ Jennifer Betts and Raymond Russell, 'Breastfeeding Attitudes and Policies', Northern Ireland Assembly Research and Information Service Briefing Paper, at www.niassembly.gov.uk/globalassets/documents/ raise/publications/2016-2021/2017/health/o917.pdf, accessed 26 February 2021.

6 Kate Boyer, 'Affect, Corporeality and the Limits of Belonging: Breastfeeding in Public in the Contemporary UK', Health \& Place, 18 (2012), pp. 552-60, here p. 553.

7 See Lisa Smyth, 'Breastfeeding's Emotional Intensity: Pride, Shame and Status', in S. Dowling, D. Pontin and K. Boyer, eds., Social Experiences of Breastfeeding: Building Bridges between Research, Policy and Practice (Bristol: Policy Press, 2018), at https://pureadmin.qub.ac.uk/ws/portalfiles/portal/140786579/5. _Chapter_1_Lisa_Smyth_FINAL_for_upload.pdf, accessed 15 February 2020.

8 Trump was not yet president when this incident occurred, but the story became public during his election campaign in 2015. See Jeremy Diamond, 'Lawyer: Donald Trump Called Me "Disgusting" for Requesting to Pump Breastmilk', CNN Politics, 29 July 2015, at https://edition.cnn.com/2015/07/29/ politics/trump-breast-pump-statement/index.html, accessed 20 February 2020. 
Laura Hughes, 'Women Who Breastfeed in the House of Commons Chamber Are "Exhibitionists", Claims MP', Daily Telegraph, 22 July 2016, at www.telegraph.co.uk/news/2016/07/22/women-whobreastfeed-in-the-house-of-commons-chamber-are-exhibit, accessed 20 November 2019. See Sara Ahmed, The Cultural Politics of Emotion (Edinburgh: Edinburgh University Press, 2004). See Rebecca Kukla's analysis of links between breastfeeding, sexuality and the domestic space, 'Ethics and Ideology in Breastfeeding Advocacy Campaigns', Hypatia, 21, 1 (2006), pp. 157-81.

Rosemary Betterton, 'Promising Monsters: Pregnant Bodies, Artistic Subjectivity and Maternal Imagination', Hypatia, 21, 1 (2006), pp. 80-100, here p. 81.

Elizabeth Grosz, Volatile Bodies (Bloomington: Indiana Universrity Press, 1994), p. 207. Virginia Schmied and Deborah Lupton, 'Blurring the Boundaries: Breastfeeding and Maternal Subjectivity', Sociology of Health \& Illness, 23, 2 (2001), pp. 234-50, here p. 246.

See Lisa Baraitser, Maternal Encounters: The Ethics of Interruption (London: Routledge, 2009). Ibid., p. 4.

Barbara Browning, 'Breastmilk Is Sweet and Salty', in André Lepecki, ed., Of the Presence of the Body: Essays on Dance and Performance Theory (Middletown, CT: Wesleyan University Press, 2004), pp. 97-109, here p. 104.

Ibid.

Dr Maria Herron of Ulster University granted Let Down's creative team access to unpublished transcripts from interviews with breastfeeding women conducted for her doctoral thesis, 'A Conceptual Analysis and Interpretation of Women's Experience of Online Breastfeeding Support' (University of Ulster, unpublished doctoral thesis, 2013). I am deeply grateful to Maria and all of the women who consented to having their interview transcripts shared.

Don Ihde, 'The Auditory Dimension', in Jonathan Sterne, ed., The Sound Studies Reader (Abingdon: Routledge, 2012), pp. 23-8, here p. 25, emphasis in the original.

Uri McMillan, 'Mammy-Memory: Staging Joice Heth, or the Curious Phenomenon of the "Ancient Negress"', Women \& Performance: A Journal of Feminist Theory, 22, 1 (2012), pp. 29-46, here p. 39. My grateful thanks to Prarthana Purkayastha for bringing my attention to McMillan's work and for suggesting the connection with Homi Bhabha's concept of the 'unhomely' later in the article.

Maggie Nelson, The Argonauts (London: Melville House, 2013), p. 123.

Lena Šimić and Emily Underwood-Lee, Editorial, Performance Research, 22, 4 (2017), pp. 1-4, here p. 1. Amber E. Kinser, Kryn Freehling-Burton and Terri Hawkes, 'Introduction', in Kinser, Freehling-Burton and Hawkes, eds., Performing Motherhood: Artistic, Activist and Everyday Enactments (Bradford, ON: Demeter Press, 2014), pp. 1-13, here p. 1.

5 Although the natural weaning age for humans has been established as falling between four and seven years of age, extended breastfeeding comes with negative social consequences in unsupportive cultures. See Kathleen A. Kendall-Tackett and Muriel Sugarman, 'The Social Consequences of Long-Term Breastfeeding', Journal of Human Lactation, 11, 3 (1995), pp. 179-83.

6 Laura Endacott, 'Performing the Maternal in Public Space', in Kinser, Freehling-Burton and Hawkes, Performing Motherhood, pp. 52-68, here p. 53.

Amanda Barnes Cooke, 'Breastfeeding in Public: Disgust and Discomfort in the Bodiless Public Sphere', Politics \& Gender, 12, 4 (2016), pp. 677-99, here p. 680.

Ibid., p. 681.

See Karen Glass, Breastfeeding and Maternity Care Research: Report Prepared for Public Health Agency (Belfast: Ipsos Mori, 2015).

See UNICEF 2018 Breastfeeding Report, at www.unicef.org/nutrition/index_resources.html, accessed 28 May 2018.

See Lisa Ashton, 'Mixed Messages Coming from Irish Government on Infant Formula and Milk Powder', report for An Taisce (National Trust for Ireland), press release published 1o October 2016, at www. antaisce.org/articles/mixed-messages-coming-from-irish-government-on-infant-formula-and-milk- 
powder, accessed 20 February 2020. Many studies have highlighted the unethical tactics used by infant-formula companies, such as Nestlé, in their promotion of formula to mothers in economically deprived areas of the global South, despite there being clear evidence that breastmilk is the safest feeding method, especially in areas where access to clean water is limited. Even in high-income countries, health outcomes for babies fed formula are worse than for breastfed babies. See George Kent, 'Global Infant Formula: Monitoring and Regulating the Impacts to Protect Human Health', International Breastfeeding Journal, 10, 6 (2015), unpaginated open access article at https://internationalbreastfeedingjournal. biomedcentral.com/articles/10.1186/s13006-014-0020-7, accessed 20 February 2020. Kukla, 'Ethics and Ideology in Breastfeeding Advocacy Campaigns', p. 163. Hollie McNish, 'Embarrassed', in McNish, Nobody Told Me: Poetry and Parenthood (London: Blackfriars, 2016), p. 153. See Glass, Breastfeeding and Maternity Care Research. Teresa Pitman, Diana West and Diane Wiessinger, The Womanly Art of Breastfeeding, 8th edn (London: Ashford Colour Press, 2015), p. 100. Wood is building here on Luce Irigaray's Sexes and Genealogies (New York: Columbia University Press, 1993). Elizabeth Wood, 'Decomposition', in Susan Leigh Foster, Sue-Ellen Case and Philip Brett, eds., Decomposition: Post-disciplinary Performance (Bloomington: Indiana University Press, 200o), pp. 201-13, here p. 202.

38 Wood, 'Decomposition', p. 202.

39 McNish, 'Embarrassed', p. 153.

40 Wood, 'Decomposition', p. 202.

41 Pitman, West and Wiessinger, The Womanly Art of Breastfeeding, pp. 23-4, emphasis in the original. Esther Leslie and Melanie Jackson, 'Unreliable Matriarchs', in Mathilde Cohen and Yuriko Otomo, eds., Making Milk: The Past, Present and Future of Our Primary Food (London: Bloomsbury, 2017), pp. 63-80, here p. 72.

43 Browning, 'Breastmilk Is Sweet and Salty', p. 108.

44 Homi Bhabha, 'The World and the Home', Social Text, 31-2 (1992), pp. 141-53, here p. 141.

45 Ibid., p. 141.

46 See Glass, Breastfeeding and Maternity Care Research.

47 Browning, 'Breastmilk Is Sweet and Salty', p. 104.

48 Nancy Scheper-Hughes in ibid., p. 104.

49 I have previously written about the corporeal effects of religious institutional oppression of feminine and 'othered' corporealities in the context of post- and neo-colonial mouldings of the dancing body in Ireland in Dance Theatre in Ireland: Revolutionary Moves (Houndmills: Palgrave, 2013). It is interesting to note Renaissance scholar Jutta Sperling's argument that Madonna Lactans paintings always had a sexualized dimension. Sperling acknowledges 'the erotic appeal of religious artworks and their strong emotional address to the viewer'. Jutta Sperling, 'Squeezing, Squirting, Spilling Milk: The Lactation of Saint Bernard and the Flemish Madonna Lactans (ca. 1430-1530), Renaissance Quarterly, 71, 3 (2018), pp. 868-918, here p. 872.

51 Naomi Yavneh, 'To Bare or Not too Bare: Sofonisba Anguissola's Nursing Madonna and the Womanly Art of Breastfeeding', in Naomi J. Miller and Naomi Yavneh, eds., Maternal Measures: Figuring Caregiving in the Early Modern Period (London: Routledge, 2000), pp. 65-82, here p. 65.

52 See Glass, Breastfeeding and Maternity Care Research.

53 Kukla, 'Ethics and Ideology in Breastfeeding Advocacy Campaigns', p. 164.

54 The Industrial Revolution in Europe saw an increase in the cost of living and the subsequent need for many women to work outside the home in order to financially support their families. The shift from a reliance on wet nurses in the nineteenth century, to formula substitutes for human milk in the twentieth, can be seen to have contributed to the rapid erosion of women's 'natural' corporeal relationship with 
breastfeeding. See Emily E. Stevens, Thelma E. Patrick and Rita Pickler, 'A History of Infant Feeding', Journal of Perinatal Education, 18, 2 (2009), pp. 32-9.

Susan Leigh Foster, 'Choreographing History: Manifesto for Dead and Moving Bodies', in Foster, ed., Choreographing History (Bloomington: Indiana University Press, 1995) pp. 3-21, here p. 6.

57 Sterne, ibid., p. 13, gives the following example: 'industrialization and urbanization decrease people's physical capacities to hear. One of the ways in which adults lose the upper range of their hearing is through encounters with loud machinery. A jackhammer here, a siren there, and the top edge of hearing begins to erode. Conflicts over what does and does not constitute environmental noise are themselves battles over what sounds are admissible in the modern landscape'. It is fascinating to conduct a reading of Let Down's engagement with the history and transformation in knowledge of breastfeeding skills in modernity through Sterne's discussion of the 'dynamic history of the body' in the context of environmental modification of hearing capacity and admissible environmental sound. As noted above, the Industrial Revolution in Europe can be seen to have contributed to the erosion of women's 'natural' corporeal relationship with breastfeeding, and the admissibility of breastfeeding in the modern landscape. Changes to 'capacity' are, of course, different to the erosion of corporeal knowledge over time, but the loss of breastfeeding knowledge can be seen to affect women's perception of their capacity to breastfeed. See Stevens, Patrick and Pickler, 'A History of Infant Feeding'.

58 Sarah Manguso, Ongoingness: The End of a Diary (Minneapolis: Graywolf Press, 2015), p. 53. My grateful thanks to Trish McTighe who directed me to Manguso's text.

59 Lisa Baraitser, Enduring Time (London: Bloomsbury, 2017), p. 75, emphasis in the original.

6o Blebs are blisters on the nipples caused by blocked milk ducts, and lactation mastitis is the painful infection and inflammation of the breast tissue that can be accompanied by fever and chills.

61 Mary Kelly in Margaret Iversen, 'The Bride Stripped Bare by Her Own Desire: Reading Mary Kelly's Post-partum Document', Discourse, 4, 4 (1981-2), pp. 75-88, here p. 75.

62 The programme for Let Down included a note to this effect, reassuring audience members that crying, cooing and gurgling babies were very welcome participants in this performance.

63 Writing of the 'sound envelope' and 'sound bath' in which subjectivity is developed, Didier Anzieu proposes that ' $[t]$ he sound space is the first psychical space. External noises, painful when they are sudden or loud, worrying internal gurglings which cannot be localized in any particular part of the body, cries that come automatically at birth, then in response to hunger, pain, anger ... - all contribute to forming that space'. Didier Anzieu, The Skin Ego, trans. Chris Turnen (New Haven: Yale University Press, 1989), p. 170.

64 Baraitser, Enduring Time, p. 72.

65 Ibid.

66 Wood, 'Decomposition', p. 209.

67 Sterne, The Audible Past, p. 13.

68 Ibid.

69 Jeroen Peeters, 'How to Knit Your Own Private Political Body?', in Jenn Joy and André Lepecki, eds., Planes of Composition: Dance, Theory and the Global (London: Seagull Books, 2009), pp. 209-32, here p. 223.

$70 \quad$ Jean Luc Nancy, Listening, trans. Charlotte Mandell (New York: Fordham Press, 2007), p. 21.

AOIFE MCGRATH (aoife.mcgrath@qub.ac.uk) is a dance practitioner-scholar and Senior Lecturer in Drama at the School of Arts, English and Languages, Queen's University Belfast. Before joining Queen's, Aoife worked as a dancer in Germany and Ireland and served as Dance Adviser for the Irish Arts Council. She leads the interdisciplinary Dance and the Maternal project at QUB, collaborating with artists, social scientists, psychologists, midwives and mothers to communicate maternal experience through dance performance. She is 
also developing a mixed-methods project on Dance and Borders with sociologists Victoria Durrer (UCD) and Peter Campbell (University of Liverpool). She has published widely on dance in Ireland, and book publications include her monograph Dance Theatre in Ireland: Revolutionary Moves (2013) and a co-edited collection (with Emma Meehan, CDaRe, Coventry), Dance Matters in Ireland: Contemporary Processes and Practices (2018). Current collaborative projects are funded by EU Horizon 2020 and AHRC/Future Screens NI. Aoife is Co-president of the Irish Society for Theatre Research, and Co-convenor of the IFTR Choreography and Corporeality Working Group. 